\title{
The ANTIOXIDANT ROLE OF N-ACETYlCYSTEINE IN TESTICULAR REMOTE INJURY AFTER SKELETAL MUSCLE ISCHEMIA AND REPERFUSION IN RATS
}

\author{
Mohammad Ashrafzadeh Takhtfooladi ${ }^{1}$, Amirali Jahanshahi ${ }^{1}$, Amir Sotoudeh ${ }^{2}$, \\ Mohammad Hadi Daneshi ${ }^{3}$, Mohammadreza Khansari ${ }^{4}$, Hamed Ashrafzadeh Takhtfooladi ${ }^{5}$
}

\author{
${ }_{1}^{1}$ Department of Surgery, Faculty of Specialized Veterinary Sciences, Science and Research Branch, Islamic Azad \\ University, Tehran, Iran \\ ${ }^{2}$ Faculty of Veterinary Sciences, Kahnooj Branch, Islamic Azad University, Kerman, Iran \\ 3 Department of Basic Science, Central Tehran Branch, Islamic Azad University, Tehran, Iran \\ ${ }^{4}$ Department of Physiology, Faculty of Specialized Veterinary Sciences, Science and Research Branch, Islamic Azad \\ University, Tehran, Iran \\ ${ }^{5}$ Faculty of Veterinary Science, Karaj Branch, Islamic Azad University, Karaj, Iran
}

\begin{abstract}
It is known that ischemia reperfusion causes remote organ injury as well as local injury. The aim of this study was to investigate whether $\mathrm{N}$-acetylcysteine has a protective effect against testicular injury after skeletal muscle ischemia reperfusion.

Twenty male Wistar rats were allocated to two groups: ischemia reperfusion (control group) and ischemia reperfusion $+\mathrm{N}$-acetylcysteine (treatment group). All animals underwent $2 \mathrm{~h}$ of ischemia by occlusion of the femoral artery and $24 \mathrm{~h}$ of reperfusion. Rats in treatment group received N-acetylcysteine $(150 \mathrm{mg} / \mathrm{kg} \mathrm{IV})$ before the reperfusion period. After the reperfusion period, testes were removed for histopathological and biochemical studies. The blood samples were collected for evaluation of serum malondialdehyde (MDA) and nitric oxide (NO) production levels.

The MDA levels in testes homogenates were found to be significantly decreased in treatment group $(\mathrm{p}<0.05)$. Treatment of $\mathrm{N}$-acetylcysteine significantly decreased serum MDA and NO levels compared to the control group ( $\mathrm{p}<0.05)$. In the control group, tissues showed histological changes. Histopathologically, there was a significant difference $(\mathrm{p}<0.05)$ between two groups.

According to histological and biochemical findings, we conclude that $\mathrm{N}$-acetylcysteine has preventive effects in the testicular injury after skeletal muscle ischemia reperfusion.
\end{abstract}

Key words: N-acetylcysteine, skeletal muscle, ischemia reperfusion, testicular injury.

\section{Introduction}

Limb ischemia reperfusion injury is one of the most common types of injuries that occur in a variety of conditions such as trauma, disease and surgery. Although there are limited experimental studies, it is known that ischemia reperfusion injury causes damage in organs not related to the initial ischemic tissues; this is termed "remote organ injury" [1-5]. As far as we know, there are only a few reports demonstrating remote organ injury following skeletal muscle ischemia reperfusion injury $[6,7]$. To our knowledge, this is the first study that shows testicular damage secondary to skeletal muscle ischemia reperfusion. On the basis of the evidence for 
the role of free radicals in mediating remote organ injury, we aimed to investigate the role of oxidative injury in testicular damage following skeletal muscle ischemia reperfusion injury and the effects of $\mathrm{N}$-acetylcysteine on testicular injury.

$\mathrm{N}$-acetylcysteine is not simply an antioxidant drug. It acts as a glutathione precursor, as a chemical reductant of oxidized thiols, as a scavenger of radical oxygen species, as a vasodilator and also improves microcirculation by restoring the decreased activity of endothelium-derived relaxing factor and may have antiaggregant properties $[8,9]$. The widely accepted use of $\mathrm{N}$-acetylcysteine in current clinical practice confers an additional advantage for its potential use in the context of trauma, compartment syndrome or ischemia reperfusion injury, as the toxicity profile of the drug is well established and clinicians already are experienced in its use [10]. There is growing evidence regarding its beneficial effects in ameliorating testicular ischemia reperfusion injury $[11,12]$. However, its role in reducing the damage in testis after skeletal muscle ischemia reperfusion has not been addressed yet. Herein, we provide evidence that free radicals may play a central role in the mechanism of testicular injury following skeletal muscle ischemia reperfusion. The results of our investigation would help to clarify the potential importance of the use of $\mathrm{N}$-acetylcysteine in situations of oxidative damage. These findings may encourage the use of antioxidants to reduce remote organ injury after skeletal muscle ischemia reperfusion.

\section{Material and methods}

All rats of the present research were kept according to the norms of the Islamic Azad University Faculty of Specialized Veterinary Sciences Tehran Iran laboratory of animal experimentations; this investigation was approved by the Committee of Ethics in Research with Animals in Islamic Azad University. The study was designed so as to minimize the number of animals required for the experiments.

\section{Experimental protocol}

Twenty male Wistar rats weighing 250-300 g (1012 weeks old) were used for this study. Animals were housed at a constant room temperature of $22^{\circ} \mathrm{C}$ under a 12-h light/12-h dark cycle for 4 days before the experiment and were fed on a commercial rodent diet and filtered tap water ad libitum. Animals were randomly allocated to two experimental groups $(\mathrm{n}=10)$ : ischemia-reperfusion (control group) and ischemiareperfusion plus $\mathrm{N}$-acetylcysteine (treatment group).

On the day of the experiment, anesthesia was induced using intramuscular ketamine hydrochloride 10\% $(50 \mathrm{mg} / \mathrm{kg}$ ) plus xylazine hydrochloride $2 \%(10 \mathrm{mg} / \mathrm{kg})$. After induction of anesthesia, each rat was placed on its back on an operating table, and its extremities were fixed to the table using sticking plaster, then the left hind limb was prepared for sterile surgery. A skin incision was made on medial surface of the left hind limb. After isolating the femoral artery and vein from the surrounding tissues, the femoral artery was clamped with a mini bulldog forceps for 2 hours.

Before clamping the femoral artery, $250 \mathrm{IU}$ of heparin was administered via the jugular vein to prevent clotting. Animals were maintained in dorsal recumbence and kept anesthetized throughout the duration of the ischemic period. Additional doses were given as necessary to maintain anesthesia during the experiment. Body temperature was maintained with a heating pad whilst the animal was under anesthesia. In treatment group $\mathrm{N}$-acetylcysteine $(150 \mathrm{mg} / \mathrm{kg})$ was injected intravenously immediately before reperfusion. Following the ischemic period, the vascular forceps was removed and then surgical site was routinely closed with 3/0 polypropylene sutures. After surgery, fluid losses were replaced by intraperitoneal administration of $5 \mathrm{ml}$ of warm isotonic saline, and rats were returned to their cages with food and water ad libitum. Postoperative analgesia was maintained using of subcutaneous nalbuphine hydrochloride $(2 \mathrm{mg} / \mathrm{kg})$. After $24 \mathrm{~h}$ of reperfusion, all animals were anesthetized again with ketamine plus xylazine and a longitudinal incision of approximately $2.0 \mathrm{~cm}$ was made to the scrotal raphe for bilateral orchiectomies (a procedure involving cord clamping and hemostasis). Right testes were processed for histopathological examination and left testes were washed with normal saline and stored in a $-20^{\circ} \mathrm{C}$ refrigerator for the evaluation of biochemical parameters. The blood samples were collected from heart and submitted for evaluation of serum malondialdehyde (MDA) and nitric oxide (NO) production levels. Then the rats were euthanized with an overdose of intra-peritoneal pentobarbital by injection $(300 \mathrm{mg} / \mathrm{kg})$.

\section{Biochemical assay}

Blood was drawn from the heart to determine the levels of MDA (end product of lipid peroxidation) and NO production. Serum was separated by centrifugation $(1000 \mathrm{rpm} 10 \mathrm{~min})$ at $4^{\circ} \mathrm{C}$. Serum samples were stored at $-80^{\circ} \mathrm{C}$ until the determination of the biochemical parameters. The MDA content of serum was determined spectrophotometrically by measuring the presence of thiobarbituric acid reactive substances [13]. Results are expressed as $\mu \mathrm{mol} / \mathrm{l}$. As serum nitrite $\left(\mathrm{NO}_{2}^{-}\right)$and nitrate $\left(\mathrm{NO}_{3}^{-}\right)$levels can be used to estimate $\mathrm{NO}$ production, we measured the concentration of these stable NO oxidative metabolites. Quantitation of $\mathrm{NO}_{2}{ }^{-}$and $\mathrm{NO}_{3}{ }^{-}$was based on the Griess reaction, in which a chromophore with strong absorbance at $545 \mathrm{~nm}$ is formed by reaction of $\mathrm{NO}_{2}{ }^{-}$with a mixture of naphtyhlethylenediamine and sulfanilamide [14]. Results are expressed as $\mu \mathrm{mol} / \mathrm{l}$. 
Table I. Histological grading according to Cosentino et al. model [16]

\begin{tabular}{ll}
\hline Grade I & $\begin{array}{l}\text { Showed normal testicular architecture with } \\
\text { an orderly, arrangement of germinal cells }\end{array}$ \\
\hline Grade II & $\begin{array}{l}\text { Injury showed less orderly, noncohesive } \\
\text { germinal cells and closely packed seminif- } \\
\text { erous tubules }\end{array}$ \\
\hline Grade III & $\begin{array}{l}\text { Injury exhibited disordered sloughed germi- } \\
\text { nal cells with shrunken pyknotic nuclei and } \\
\text { less distinct seminiferous tubule borders }\end{array}$ \\
\hline Grade IV & $\begin{array}{l}\text { Injury defined seminiferous tubules that } \\
\text { were closely packed with coagulative } \\
\text { necrosis of the germinal cells }\end{array}$ \\
\hline
\end{tabular}

MDA levels in the testicular tissue were measured by the method developed by Ohkawa [15]. This is based on the measurement of thiobarbituric acid malondialdehyde absorbance. The tissue MDA levels were expressed as $\mathrm{nmol} / \mathrm{g}$ tissue.

\section{Histopathological examination}

The right extracted testes were immediately placed into $10 \%$ formalin solution. The tissue specimens were placed in paraffin blocks, sectioned at $5 \mu \mathrm{m}$, and stained with hematoxylin-eosin (HE). The sections were examined under light microscope (Olympus BH2, Olympus Optical Co, Tokyo, Japan) by a pathologist who was blinded to the experiment and data. The histological parameters were scored according to Cosentino and colleagues' classification (Table I) [16].

\section{Statistical analysis}

Statistical analyses were carried out using SPSS statistical software package (version 18). Distribution of the groups was analyzed with one sample Kol-

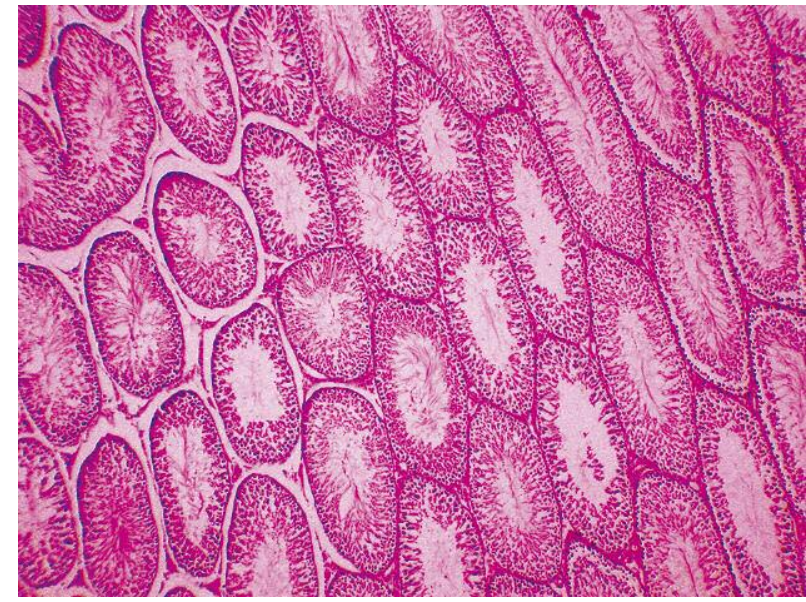

Fig. 1. Light microscopic view of testes tissues from treatment group showing normal seminiferous tubule morphology with orderly arrangement of germinal cells. HE; staining; magnification of $4 \times 10$
mogorov-Smirnov test. The Mann-Whitney U-test and t-test were employed to analyze two groups consecutively. Results were expressed as the mean \pm standard deviation. Values of $\mathrm{p}<0.05$ were considered as statistically significant.

\section{Results}

The experimental procedure was well tolerated and no animal died during the experiment. One of the most interesting observations in our study is the presence of sloughed germinal cells within the seminiferous tubules and disorganization in rat testes after skeletal muscle ischemia reperfusion injury. The testicular injury score increased significantly in the control group compared with the $\mathrm{N}$-acetylcysteine treated group $(\mathrm{p}<0.05)$. Histopathologically, the rats in the treatment group had essentially normal seminiferous tubule morphology (Figs. 1 and 2). In the control group (Figs. 3 and 4), the lesions varied between grade III and grade IV. In this group, edema, congestion, hemorrhage between seminiferous tubules and necrosis of the germinal cells were predominant features in sections. However, in the treatment group, more rats had grade I and II injury and histopathological features which were significantly lower than the control group ( $\mathrm{p}<0.05)$ (Table II).

The serum MDA and NO values in the control group were elevated by ischemia reperfusion injury; however, $\mathrm{N}$-acetylcysteine treatment significantly decreased the ischemia reperfusion-induced elevation in the MDA and NO levels ( $p<0.05)$. The level of MDA was significantly increased in the testes tissue of the control group $(\mathrm{p}<0.001)$.

\section{Discussion}

Ischemia reperfusion injury not only affects local tissue but can also result in life-threatening damage to

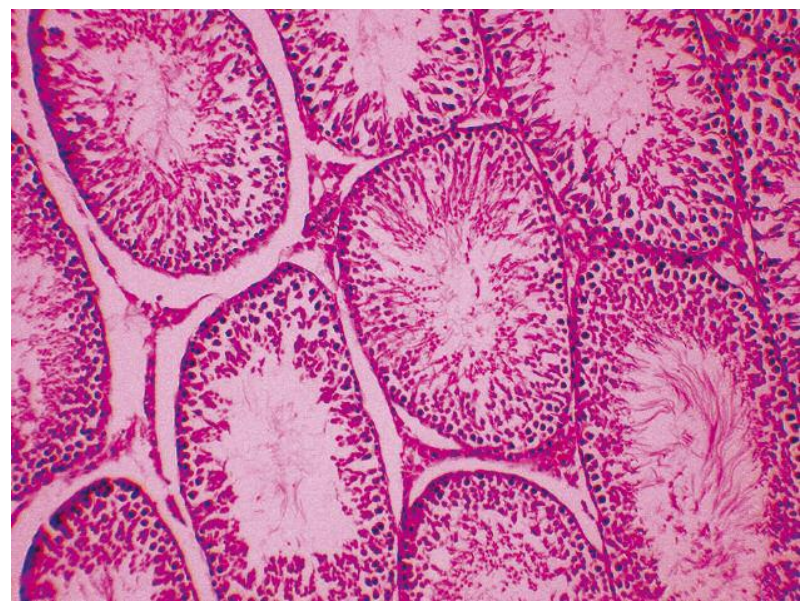

Fig. 2. Light microscopic view of testes tissues from treatment group. Magnification of $10 \times 10$, HE staining 


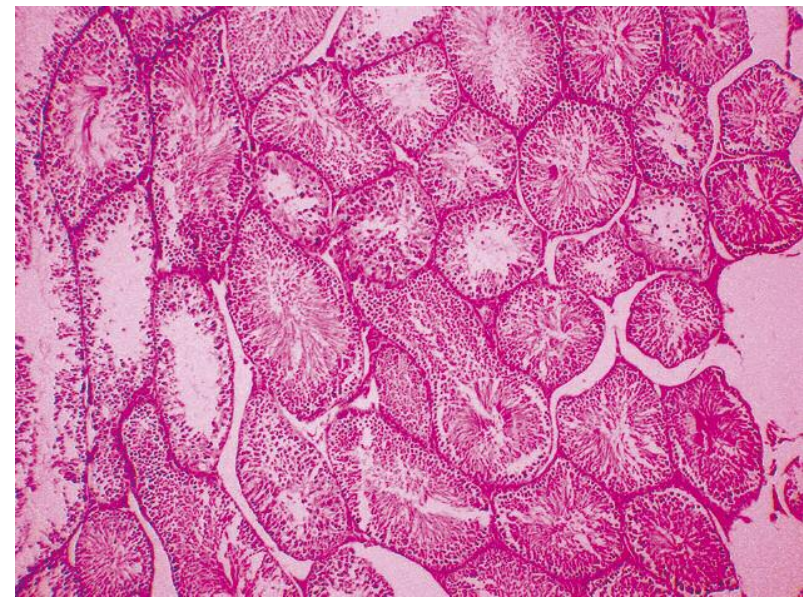

Fig. 3. Light microscopic view of testes tissues from control group showing disordered, sloughed germinal cells within the seminiferous tubules. HE staining; magnification of $4 \times 10$

remote organs such as lungs, heart, liver, kidneys and testes [17-20]. Many previous reports suggest that reperfusion following prolonged ischemia stimulates excessive production of reactive oxygen species and triggers the participation of neutrophils causing an inflammatory reaction. In a normal environment, superoxide dismutase, which converts superoxide into hydrogen peroxide, acts to prevent superoxide from damaging tissue [21], but in reperfusion injury, these natural defenses may be overcome and hydrogen peroxide is converted into the hydroxyl radical, which can damage a wide variety of biological molecules including amino acids, membrane transport proteins and nucleic acids [22]. The most important form of damage caused by oxygen free radicals is due to lipid peroxidation, which results in functional and structural cell alterations [23]. On the other hand, the mechanism of remote organ injury is poorly understood. Oxidant agents as well as inflammatory mediators such as tumor necrosis factor- $\alpha$, interleukin-1 [24], and nitric oxide (NO) [25], adhesion molecules such as intercellular adhesion molecule $1[24,26]$, and complement [27]

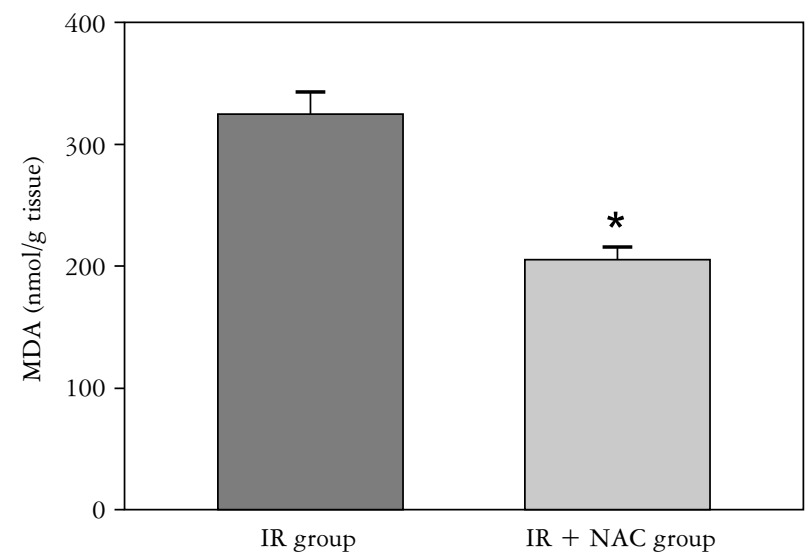

Fig. 5. Levels of malondialdehyde (MDA) in tissues $* p=0.000$

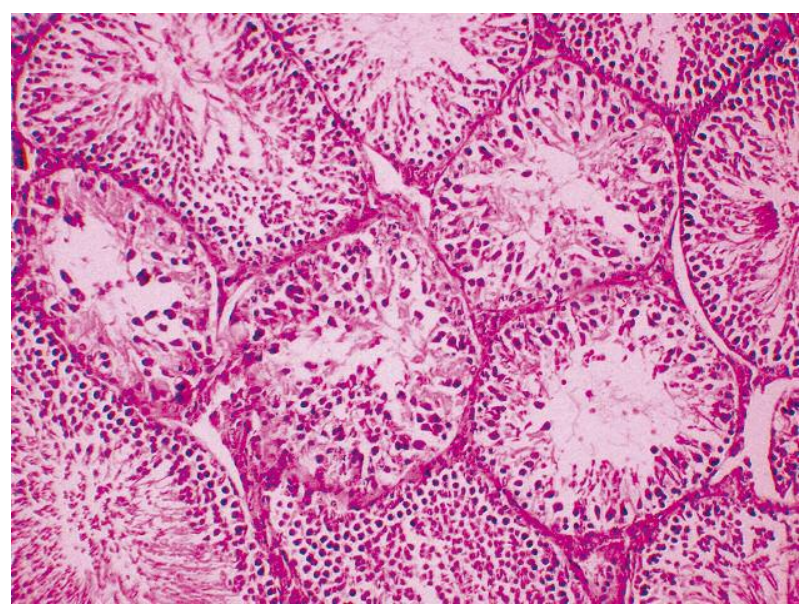

Fig. 4. Light microscopic view of testes tissues from control group. HE staining; magnification of $10 \times 10$

have been implicated in the pathogenesis of remote organ injury [20]. The results of Eşrefoğlu et al. indicated that myocardial ischemia reperfusion induces severe testicular damage and antioxidant agents have protective effects on testicular injury after myocardial ischemia reperfusion. Their data emphasized that oxygenbased reactants may play a central role in remote organ injury [20].

$\mathrm{N}$-acetylcysteine is a small molecule containing a thiol group, which has antioxidant properties, and is freely filterable with ready access to intracellular compartments $[28,29]$. The diversity of pharmacological applications of $\mathrm{N}$-acetylcysteine is due, mainly to the chemical properties of the cysteinyl thiol group of its

Table II. Scores of testis histological changes

\begin{tabular}{lcc}
\hline GrouP & $\mathbf{N}$ & MEAN \pm SD $^{*}$ \\
\hline Control & 10 & $3.1 \pm 0.37$ \\
\hline Treatment & 10 & $1.4 \pm 0.51$ \\
\hline
\end{tabular}

* There is significant difference $(p=0.000)$ between two groups.

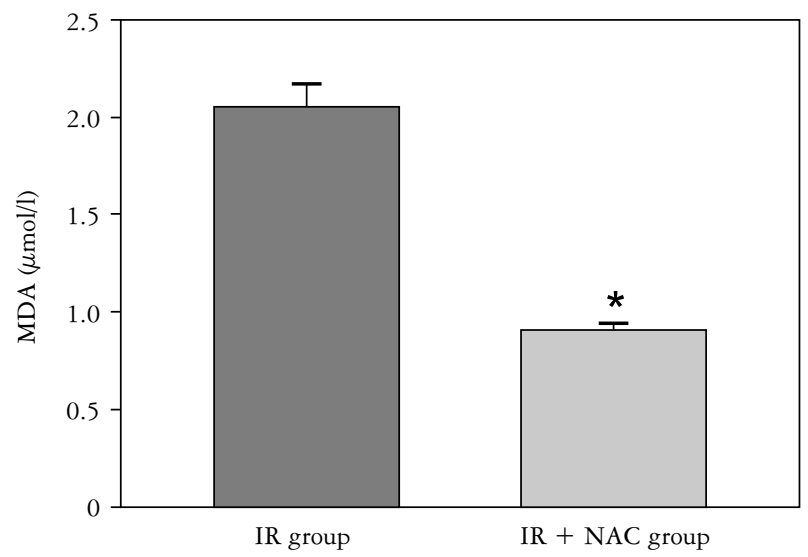

Fig. 6. Levels of malondialdehyde (MDA) in serum $* p=0.000$ 


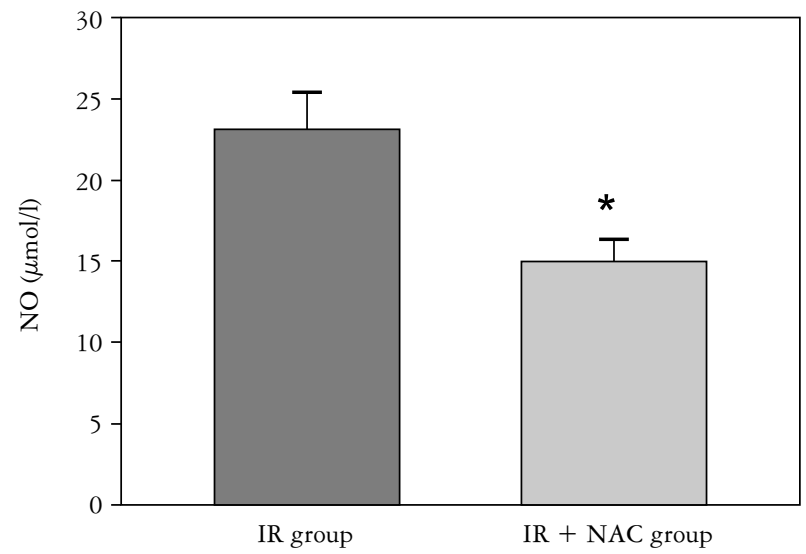

Fig. 7. Levels of nitric oxide (NO) in serum $* p=0.000$

molecule, since the ability of reduced thiol groups to scavenge oxygen free radicals is well established [30, 31]. Because of these properties, $\mathrm{N}$-acetylcysteine is widely used in clinical practice as an antioxidant.

Recently administered $\mathrm{N}$-acetylcysteine was shown to protect against ischemia reperfusion injuries in local and remote organs and it was suggested that this protective effect may be due to its ability to scavenge free radicals $[18,19,31]$. There is growing evidence regarding its beneficial effects in ameliorating testicular ischemia reperfusion injury $[11,12]$. In an experimental study Aktas et al. suggested that the administration of $\mathrm{N}$-acetylcysteine $(20 \mathrm{mg} / \mathrm{kg}) 60 \mathrm{~min}$ before spermatic cord detorsion may have a protective effect in rat experimental testicular torsion/detorsion models [11]. This observation was supported by Cay et al., who demonstrated that $\mathrm{N}$-acetylcysteine may be a potential protective agent for preventing the negative biochemical changes related to oxidative stress in testicular injury caused by spermatic cord torsion [12]. However, the protective effect of $\mathrm{N}$-acetylcysteine on testes from skeletal muscle ischemia reperfusion injury has not been studied to date. In the current study, we tested the hypothesis that $\mathrm{N}$-acetylcysteine could protect the testes from remote organ injury after skeletal muscle ischemia reperfusion.

In the present study, serum MDA and NO levels were higher in the control group than those of the treatment group. These results strongly suggest that ischemia reperfusion mediated local and remote organ injury is oxygen dependent, as indicated by the increase in the levels of established markers of oxidative stress. MDA, a product of lipid peroxidation, is generated as a result of toxic effects of active oxygen radicals, which destroy unsaturated fatty acids in the cell membranes [32]. Recently, the production of large amounts of $\mathrm{NO}$, a free radical, produced by the inducible isoform of NO synthase has been implicated as a cytotoxic factor in a variety of pathophysiological processes $[33,34]$. The cytotoxicity of $\mathrm{NO}$ is, in part, mediated by peroxynitrite anion, a reactive oxidant species formed from $\mathrm{NO}$ and superoxide an almost diffusion-controlled rate [35-37]. In summary, the present results demonstrate that testicular damage occurs following skeletal muscle ischemia reperfusion with an increase of $\mathrm{NO}$ and MDA. Inhibition of $\mathrm{NO}$ by an antioxidant agent, $\mathrm{N}$-acetylcysteine, prevented testicular damage, suggesting that increased $\mathrm{NO}$ production is involved in the testes injury induced by the skeletal muscle ischemia reperfusion. These results partially explain the mechanism of testes injury after skeletal muscle ischemia reperfusion and suggest that inhibiting NO production may be a novel pharmacological approach to prevent cell injury.

The results of the present study support the view that temporary occlusion of the femoral artery induced testicular injury in rats. Our results are consistent with those of testicular ischemia and ischemia reperfusion injury [38-41]. Our data demonstrate that $\mathrm{N}$-acetylcysteine significantly reduces the severity of testes injury, decreasing edema, congestion, hemorrhage between seminiferous tubules and necrosis of the germinal cells in the testes after skeletal muscle ischemia reperfusion injury.

\section{Conclusions}

The results of the present study showed that skeletal muscle ischemia reperfusion induced testicular injury in rats. However, administration of the $\mathrm{N}$-acetylcysteine treatment significantly decreased testes injury induced by skeletal muscle ischemia reperfusion according to our histological and biochemical findings. These results suggest the possibility of clinical application of $\mathrm{N}$-acetylcysteine in ischemia reperfusion injury of the testis. Further studies are required to clarify the exact mechanism mediating testis injury following skeletal muscle ischemia reperfusion.

The authors declare no conflict of interest.

\section{References}

1. Zhao H, Montalto MC, Pfeiffer KJ, Hao L, Stahl GL. Murine model of gastrointestinal ischemia associated with complementdependent injury. J Appl Physiol 2002; 93: 338-345.

2. Meyer K, Brown MF, Zibari G, et al. ICAM-1 upregulation in distant tissues after hepatic ischemia/reperfusion: a clue to the mechanism of multiple organ failure. J Pediatr Res 1998; 33: 350-353.

3. Kelly KJ. Distant effects of experimental renal ischemia/reperfusion injury. J Am Soc Nephrol 2003; 14: 1549-1558.

4. Mutlu G, Abbasoglu L, Dogru-Abbasoglu S, et al. Morphological changes and lipid peroxidation in renal tissues of young rats following intestinal ischemia-reperfusion. Pediatr Surg Int 2002; 18: $337-340$.

5. Zhou JL, Jin GH, Yi YL, et al. Role of nitric oxide and peroxynitrite anion in lung injury induced by intestinal ischemia-reperfusion in rats. World J Gastroenterol 2003; 9: 1318-1322.

6. Kim WG, Lee BH, Seo JW. Light and electron microscopic analyses for ischemia-reperfusion lung injury in an ovine cardiopulmonary bypass model. Perfusion 2001; 16: 207-214. 
7. Meldrum DR, Donnahoo KK. Role of TNF in mediating renal insufficiency following cardiac surgery: evidence of a postbypass cardiorenal syndrome. J Surg Res 1999; 85: 185-199.

8. Tredger JM. N-acetylcysteine: not a simply glutathione precursor. Transplantation 2000; 69:703-704.

9. Arstall MA, Yang J, Stafford I, et al. N-acetylcysteine in combination with nitroglycerin and streptokinase for the treatment of evolving acute myocardial infarction. Safety and biochemical effects. Circulation 1995; 92: 2855-2862.

10. Radomska-Leśniewska DM, Skopiński P. N-acetylcysteine as an anti-oxidant and anti-inflammatory drug and its some clinical applications. Centr Eur J Immunol 2012; 37: 57-66.

11. Aktas BK, Bulut S, Baykam MM, et al. The effects of $\mathrm{N}$-acetylcysteine on testicular damage in experimental testicular ischemia/reperfusion injury. Pediatr Surg Int 2010; 26: 293-298.

12. Cay A, Alver A, Küçük M, et al. The effects of N-acetylcysteine on antioxidant enzyme activities in experimental testicular torsion. J Surg Res 2006; 131: 199-203.

13. Sahna E, Parlakpinar H, Ozturk F, et al. The protective effects of physiological and pharmacological concentrations of melatonin on renal ischemia-reperfusion injury in rats. Urol Res 2003; 31: 188-193.

14. Cortas NK, Wakid NW. Determination of inorganic nitrate in serum and urine by a kinetic cadmium-reduction method. Clin Chem 1990; 36: 1440-1443.

15. Ohkawa H, Ohishi N, Yagi K. Assay for lipid peroxides in animal tissues by thiobarbituric acid reaction. Anal Biochem 1979; 95: 351-358.

16. Cosentino MJ, Nishida M, Rabinowitz R, et al. Histological changes occurring in the contralateral testes of prepubertal rats subjected to various durations of unilateral spermatic cord torsion. J Urol 1985; 133: 906-911

17. Grace PA. Ischaemia-reperfusion injury. Br J Surg 1994; 81: 637-647.

18. Sotoudeh A, Takhtfooladi MA, Jahanshahi A, et al. Effect of $\mathrm{N}$-acetylcysteine on lung injury induced by skeletal muscle ischemia-reperfusion: histopathological study in rat model. Acta Cir Bras 2012; 27: 168-171.

19. Takhtfooladi MA, Jahanshahi A, Jahanshahi GH, et al. Protective effect of $\mathrm{N}$-acetylcysteine on kidney as a remote organ after skeletal muscle ischemia-reperfusion. Acta Cir Bras 2012; 27 : 611-615.

20. Eșrefoğlu M, Gül M, Parlakpinar H, Acet A. Effects of melatonin and caffeic acid phenethyl ester on testicular injury induced by myocardial ischemia/reperfusion in rats. Fundam Clin Pharmacol 2005; 19: 365-372.

21. Anaya-Prado R, Toledo-Pereyra LH, Lentsch AB, Ward PA. Ischemia/reperfusion injury. J Surg Res 2002; 105: 248-258.

22. Halliwell B, Gutteridge JM, Cross CE. Free radicals, antioxidants, and human disease: where are we now? J Lab Clin Med 1992; 119: 598-620

23. Slater TF. Free-radical mechanisms in tissue injury. Biochem J 1984; 222: 1 - 15 .

24. Kelly KJ. Distant effects of experimental renal ischemia/reperfusion injury. J Am Soc Nephrol 2003; 14: 1549-1558.

25. Zhou JL, Jin GH, Yi YL, Zhang JL, Huang XL. Role of nitric oxide and peroxynitrite anion in lung injury induced by intestinal ischemia-reperfusion in rats. World J Gastroenterol 2003; 9: 1318-1322.

26. Meyer K, Brown MF, Zibari G, et al. ICAM-1 upregulation in distant tissues after hepatic ischemia/reperfusion: a clue to the mechanism of multiple organ failure. J Pediatr Res 1998: 33: 350-353.

27. Zhao H, Montalto MC, Pfeiffer KJ, Hao L, Stahl GL. Murine model of gastrointestinal ischemia associated with complementdependent injury. J Appl Physiol 2002; 93: 338-345.

28. De Vries N, De Flora S. N-acetyl-l-cysteine. J Cell Biochem 1993; 17: $270-277$.
29. Holodines MR. Clinical pharmacokinetics of N-acetylcysteine. Clin pharmacokinetics 1991; 20: 123-134.

30. Aruoma $\mathrm{OH}$, Halliwell B, Hoey BM. The antioxidant action of $\mathrm{N}$-acetylcysteine: its reaction with hydrogen peroxide, hydroxyl radical, superoxide, and hypochlorous acid. Free Radic Biol Med 1989; 6: 593-597.

31. Cuzzocrea S, Mazzon E, Costantino G, et al. Effedts of N-acetylcysteine in a rat model of ischemia and reperfusion injury. Cardiovasc Res 2000; 47: 537-548.

32. Parlakpinar H, Sahna E, Ozer MK, et al. Physiological and pharmacological concentrations of melatonin protect against cisplatin induced acute renal injury. J Pineal Res 2002; 33: 161-166.

33. Tavaf-Motamen H, Miner TJ, Starnes BW, Shea-Donohue T. Nitric oxide modulates acute lung injury by modulation of inflammation. J Surg Res 1998; 78: 137-142.

34. Li H, Forstermann U. Nitric oxide in the pathogenesis of vascular disease. J Pathol 2000; 190: 244-254.

35. Szabo C. Pathophysiological role of peroxynitrite in shock, inflammation, and ischemia/reperfusion injury. Shock 1996; 6: 79-88.

36. Pryor WA, Squadrito GL. The chemistry of peroxynitrite: a product from the reaction of nitric oxide with superoxide. Am J Physiol 1995; 268: L699-L722.

37. Cuzzocrea S, Zingarelli B, Caputi AP. Role of constitutive nitric oxide synthase and peroxynitrite production in a rat model of splanchnic artery occlusion shock. Life Sci 1998; 63: 789-799.

38. Nguyen L, Lievano G, Ghosh L, et al. Effect of unilateral testicular torsion on blood flow and histology of contralateral testes. J Pediatr Surg 1999; 34: 680-683.

39. Goto A. Histological and immunohistochemical studies on the damage of contralateral testis following the unilateral testicular torsion in Wistar rats. Nippon Hinyokika Gakkai Zasshi 1991; 82: 726-733.

40. Turner TT, Tung KS, Tomomasa H, Wilson LW. Acute testicular ischemia results in germ cell-specific apoptosis in the rat. Biol Reprod 1997; 57: 1267-1274.

41. Jiang HM, Li M, Li YP. Experimental study on isolated testes with ischemia/reperfusion injury. Zhongguo Xiu Fu Chong Jian Wai Ke Za Zhi 2001; 15: 377-381.

\section{Address for correspondence}

\section{Mohammad Ashrafzadeh Takhtfooladi}

Department of Surgery

Faculty of Specialized Veterinary Sciences

Science and Research Branch

6589854256 Tehran, Iran

e-mail: dr_ashrafzadeh@yahoo.com 